\title{
Optimal Allocation of DG and DSTATCOM in Radial Distribution System Using Cuckoo Search Optimization Algorithm
}

\author{
T. Yuvaraj, ${ }^{1}$ K. Ravi, ${ }^{1}$ and K. R. Devabalaji ${ }^{2}$ \\ ${ }^{1}$ School of Electrical Engineering, VIT University, Vellore, India \\ ${ }^{2}$ Department of Electrical Engineering, MVJ College of Engineering, Bengaluru, India \\ Correspondence should be addressed to K. R. Devabalaji; eeedevabalaji@gmail.com
}

Received 6 August 2016; Revised 24 September 2016; Accepted 30 January 2017; Published 19 February 2017

Academic Editor: Nikos D. Lagaros

Copyright (C) 2017 T. Yuvaraj et al. This is an open access article distributed under the Creative Commons Attribution License, which permits unrestricted use, distribution, and reproduction in any medium, provided the original work is properly cited.

\begin{abstract}
This paper proposes a new approach to determine the optimal location and sizing of Distributed Generation (DG) and Distribution STATic COMpensator (DSTATCOM) simultaneously in the distribution network. The objective function is formulated to minimize the total power losses of the system subjected to equality and inequality constraints. Loss sensitivity factor (LSF) and Voltage Stability Index (VSI) are used to predetermine the optimal location of DG and DSTATCOM, respectively. Recently developed nature-inspired cuckoo search algorithm (CSA) has been used to determine the optimal size of both DG and DSTATCOM. In the present work, five different cases have been considered during DG and DSTATCOM placement to access the performance of the proposed technique. To check the feasibility, the proposed method is tested on IEEE 12-bus, 34-bus, and 69-bus radial distribution system and the results were compared with other existing techniques.
\end{abstract}

\section{Introduction}

Generally, the majority of the distribution network loads are inductive in nature. So the network power factor will be lagging in nature. It leads to increasing the power losses, causes poor voltage profile, and creates network security problems in the distribution networks. The distribution system total power losses can be divided into real and reactive power losses. Compared to the effect of reactive power losses in the system, the real power losses $\left(I^{2} R\right)$ affect the efficiency of the power transfer and lead to poor voltage profile [1].

Studies indicated that $10-13 \%$ of the total power generation is consumed as $I^{2} R$ losses (real power loss) at the distribution system [2-5]. Hence, it is necessary to place the compensating devices in the distribution system to reduce power losses and improve the voltages between the buses. In this work, DG and DSTATCOM units are placed simultaneously in the distribution for compensation. There are different benefits of simultaneous allocation of DG and DSTATCOM in the distribution system including reducing system power loss, voltage profile enhancement, power factor correction, load balancing, power quality improvement, on-peak operating costs reduction, releasing the overloading of distribution lines, system stability improvement, pollutant emission reduction, and increased overall energy efficiency.

In recent years Distributed Generation integration plays an important role in distribution system planning which results in major system upgrade, power loss reduction, and voltage profile enhancement and, finally, improving overall system reliability. DG is defined as electricity generation with limited size generator connected to the distribution system. Several factors have been responsible for the appearance of DG in radial distribution system. The environment issues such as reducing the greenhouse effect, reduction of fossil fuel, and current scenario of deregulation of electricity market recommend the requirement for more flexible electric systems [6].

STATCOM was initially developed for transmission systems to regulate the voltage profile so as to provide reactive power compensation and power factor control; then similar 
concept has been started to be applied to distribution systems $[7,8]$. DSTATCOM is used to improve the voltage profile, power factor, and voltage stability of the distribution system. DSTATCOM is a shunt connected voltage source converter (VSC) that can be used to compensate power quality issues [9]. The DSTATCOM is a fast and rapid compensating device which enhances voltage profile and power losses reduction through injection of compensating current into the system [10]. It is advised to place the DG and DSTATCOM units at optimal place with optimal size to achieve maximum benefits of the system. Improper placement of DG and DSTATCOM units will lead to collapse and even endanger the entire system operation [11]. The main objective of DG placement is to compensate the real power, whereas the DSTATCOM placement is to compensate reactive power in the distribution system.

In the recent past, several population based metaheuristic techniques such as Genetic Algorithm (GA), Ant Colony Optimization (ACO), Immune Algorithm (IA), Differential Evolution Algorithm (DEA), Firefly Algorithm (FA), Particle Swarm Optimization (PSO), Teaching Learning Based Optimization (TLBO), Artificial Bee Colony (ABC), Harmony Search Algorithm (HSA), and Bat Algorithm (BA) have shown their potential to solve optimal DSTATCOM placement problem [13-18] or optimal DG placement problem [1927].

A lot of research work has been carried out to successfully optimize the siting and sizing problems of DG and DSTATCOM devices when allocated separately. Though, only a single research work has been done in simultaneous allocation of DG and DSTATCOM in the radial distribution networks. The authors have used particle swarm optimization algorithm for the problem of simultaneous placement of DG and DSTACOM with an objective of total power loss minimization [12].

Cuckoo Search Algorithm (CSA) [28] is one of the new nature-inspired algorithms that has been proposed recently to solve complex optimization problems. CSA can be used to efficiently solve global optimization problems [29] as well as NP-hard problems that cannot be solved by exact solution methods [30]. The most powerful feature of CS is its use of Levy flights to update the search space for generating new candidate solutions. This mechanism allows the candidate solutions to be modified by applying many small changes during the iteration of the algorithm. This in turn makes a compromised relationship between exploration and exploitation which enhance the search capability [31]. To this end, recent studies proved that CSA is potentially far more efficient than GA and PSO [32]. In addition, it is a simple and population based stochastic optimization algorithm. Moreover, it requires less control parameters to be tuned. Also, it is a compatible optimization tool for power system controller design. Such feature has motivated the use of CSA to solve different kinds of engineering problems such as multiobjective scheduling problem [33], reliability optimization problems [34], DG allocation in distribution network [35], economic dispatch [36], network reconfiguration, and Distributed Generation allocation in distribution network [37].

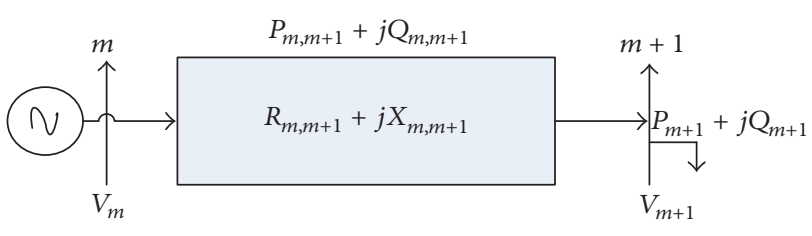

FIGURE 1: Sample distribution system.

The present work is aimed at developing a fast and new technique to determine the optimal location and sizing of DG and DSTATCOM for minimize the power losses and enhance voltage profile. The optimal location of the DG and DSTATCOM can be identified using LSF and VSI, respectively. The optimal size of the DG and DSTATCOM can be determined by using cuckoo search algorithm. The novelty of this work is implementing an integrated approach of LSF and VSI with CSA to determine the optimal location and sizing of DG and DSTATCOM for the sake of power loss minimization and voltage profile enhancement. Another advantage of this work is that multiple DG and DSTATCOM are placed simultaneously in the radial distribution system. The comparison over single and multiple DG and DSTATCOM placement has been analyzed and it gives encouraging results. In addition to that, the total operating cost (TOC) of the DG and DSTATCOM simultaneously has been considered for all the cases which is not considered before in the literature. To show the effectiveness of the proposed method, it has been applied on standard IEEE test radial distribution system and the obtained results are compared with other techniques.

\section{Problem Formulation}

2.1. Load Flow Analysis. The direct approach for distribution load flow is used to find the power losses and also the voltage at each branch [38]. The single line diagram of a sample distribution system is shown in Figure 1.

The voltage at node $m+1$ is given by

$$
V_{m+1}=V_{m}-I\left(R_{m, m+1}+j X_{m, m+1}\right),
$$

where $V_{m+1}$ is the voltage magnitude of the bus $m+1, V_{m}$ is the voltage magnitude of the bus $m, R_{m, m+1}$ is the resistance of the line between $m$ and $m+1$, and $X_{m, m+1}$ is the reactance of the line between $m$ and $m+1$.

$$
I=[\mathrm{BIBC}][i]
$$

where $I$ is the branch current. BIBC is the bus current injection to branch current matrix.

$$
i_{m}=\frac{\left(P_{m+1}+j Q_{m+1}\right)^{*}}{V_{m}}
$$

where $P_{m+1}$ is the real power load at bus $m+1, Q_{m+1}$ is the reactive power load at bus $m+1$, and $i_{m+1}$ is the current injected at node $m+1$. 
The real and reactive power losses of the system are calculated by using the following equation:

$$
\begin{gathered}
P_{\text {loss }}(m, m+1)=\left(\frac{P_{m, m+1}^{2}+Q_{m, m+1}^{2}}{\left|V_{m}\right|^{2}}\right) R_{m, m+1} \\
Q_{\text {loss }}(m, m+1)=\left(\frac{P_{m, m+1}^{2}+Q_{m, m+1}^{2}}{\left|V_{m}\right|^{2}}\right) X_{m, m+1},
\end{gathered}
$$

where $P_{m, m+1}$ is the real power flow in the line between $m$ and $m+1$ and $Q_{m, m+1}$ is the reactive power flow in the line between $m$ and $m+1$.

The total real and reactive power losses of the system can be easily found by summing all the branch power losses and it is expressed in

$$
P_{T, \text { Loss }}=\sum_{m=1}^{\mathrm{nb}} P_{\text {Loss }}(m, m+1),
$$

where $\mathrm{nb}$ is the number of the branches.

2.2. Objective Function. The objective function $(F)$ of the proposed work is formulated to minimize the power losses of the system.

The mathematical formulation of the objective function is given by

$$
\operatorname{Minmize}(F)=\min \left(P_{T, \text { Loss }}\right) \text {, }
$$

where $P_{T, \text { Loss }}$ is the total power loss of the radial distribution system.

Constraints. The optimal allocation of DG and DSTATCOM in distribution system is subjected to the following constraints.

(a) Power Balance. Power generation is equal to the power demand and power losses.

\section{Voltage Limit}

$$
V_{m, \min } \leq\left|V_{m}\right| \leq V_{m, \max }
$$

where $V_{m, \min }$ and $V_{m, \max }$ are the minimum and maximum voltage limits at bus $m$, respectively.

\section{(b) Real Power Compensation}

$$
P_{D m}^{\min } \leq P_{D m} \leq P_{D m}^{\max }, \quad m=1, \ldots, N_{B},
$$

where $P_{D m}^{\min }$ and $P_{D m}^{\max }$ are the minimum and maximum real power limits of compensated bus $m$, respectively.

\section{(c) Reactive Power Compensation}

$$
Q_{c m}^{\min } \leq Q_{c m} \leq Q_{c m}^{\max }, \quad m=1, \ldots, N_{B},
$$

where $Q_{c m}^{\min }$ and $Q_{c m}^{\max }$ are the minimum and maximum reactive power limits of compensated bus $m$, respectively.

\section{Optimal Location}

The loss sensitivity factor is used to preidentify the optimal location of the DG and the voltage stability index is used to preidentify the optimal location of the DSTATCOM. The optimal size of the DG and DSTATCOM will be obtained using cuckoo search algorithm. Another advantage of preidentifying the optimal location is that it has to reduce the search space of the optimization process.

3.1. Loss Sensitivity Factor. The loss sensitivity factor is used to identify the optimal location for DG placement. The node which has the highest value of LSF with respect to the real power has more chance to place DG $[39,40]$. The LSF values of all buses are calculated, and then they are arranged in descending order. The top most LSF value has more chance to be selected as a candidate location of DG.

Equation (4) is partially differentiated with respect to real power and it is given by

$$
\frac{\partial P_{\text {loss }}(m, m+1)}{\partial P_{m, m+1}}=\frac{2 P_{m, m+1} R_{m, m+1}}{\left|V_{m}\right|^{2}} .
$$

3.2. Voltage Stability Index. There are many indices used to check the power system security level. In this section, a new steady state voltage stability index is used in order to identify the node, which has more chance of voltage collapse and it is expressed in $(12)[2,41,42]$. In order to attain the stable operation of the radial distribution system, the VSI should be $m \geq 0$. The voltage stability at each node is calculated from the power flow using (12). The node which has the low value of VSI has more chance to install DSTATCOM.

$$
\begin{aligned}
\operatorname{VSI} & (n)=\left|V_{m+1}\right|^{4} \\
& -4\left[P_{m, m+1} * X_{m, m+1}-Q_{m, m+1} * R_{m, m+1}\right]^{2} \\
& -4\left[P_{m, m+1} * R_{m, m+1}+Q_{m, m+1} * X_{m, m+1}\right] \\
& \cdot\left|V_{m, m+1}\right|^{2} .
\end{aligned}
$$

\section{Cuckoo Search Algorithm}

Cuckoo search algorithm is introduced by Yang and Deb [28, 29]. CSA have two main operators. One is direct search based on Levy flights and another one is random search based on the probability for a host bird to discover an alien egg in its nest. The parameters used in cuckoo search algorithm are as follows:

$\mathrm{N}$ : number of nests or different solutions (25).

Pa: discovery rate of alien eggs/solutions (0.25).

$\mathrm{Nd}$ : dimension search space (1 or 3 ).

Lb and Ub: the lower and upper bounds limits.

CSA consists of three steps. They are as follows:

(i) Every cuckoo lays one egg at a time and dumps its egg in a randomly chosen nest. 
(ii) The best nests with high quality of eggs will carry over to the next generation.

(iii) The number of available host nests is fixed, and the egg laid by a cuckoo is discovered by the host bird.

Cuckoos are attractive birds; they not only make beautiful sounds but also have fantastic reproduction strategy. Some of the species in cuckoo like Ani and Guira lay their eggs in common nests, though they may remove other's eggs to rise the hatching probability of their own eggs. The cuckoo eggs may hatch earlier than that of their host eggs. When the first cuckoo eggs is hatched, the first action is to remove the host eggs by blindly pushing out the egg from the nest. The cuckoo chick may also mimic the call of host chick to increase the feeding opportunity.

The term Levy flight was introduced by Benoit Mandelbrot, who used this term for one specific definition of the distribution of step size. Naturally most of the animals search for (cuckoo bird will search for host nest) their food in the random manner (the next step is always based on the current location and the probability of moving to the next location). It can be modeled with a Levy distribution (a continuous probability distribution for nonnegative random variables) know as Levy flights.

The cuckoo bird will find the best nest to lay their egg (solution) to maximize their eggs survival rate. Actually every cuckoo lays only one egg at a time. The high quality eggs (optimal value) which are more similar to the host bird's eggs have more chance to develop (next generation) and become a mature cuckoo. Unhealthy eggs (not optimal value) are identified by host bird with a probability $\mathrm{Pa} €[0,1]$ and these eggs are thrown away or the nest is discarded, and the new nest is built at a new location. A randomly distributed initial population of host nest is generated and then the population of solutions is subjected to repeated cycles of the search process of the cuckoo birds. The cuckoo randomly chooses the nest position to lay egg using

$$
\begin{gathered}
X_{p q}^{\mathrm{gen}+1}=X_{p q}^{\mathrm{gen}}+S_{p q} * \operatorname{Levy}(\lambda) * \alpha \\
\operatorname{Levy}(\lambda)=\left|\frac{\Gamma(1+\lambda) * \sin (\pi * \lambda / 2)}{\Gamma(1+\lambda / 2) * \lambda * S^{(\lambda-1) / 2}}\right|^{1 / \lambda},
\end{gathered}
$$

where $\lambda$ is constant $(1<\lambda \leq 3), \alpha$ is a random number generated between $[-1,1], \Gamma$ is gamma function, and $S>0$, which is step size.

The step size can be obtained using

$$
S_{p q}=X_{p q}^{\mathrm{gen}}-X_{f q}^{\mathrm{gen}}
$$

where $p, f \in\{1,2, \ldots, m\}$ and $q \in\{1,2, \ldots, D\}$ are randomly chosen indexes and $f$ is chosen randomly but its value must be different from $p$.

The host bird will identify the cuckoo egg and choose the high quality egg with probability of using

$$
\operatorname{pro}_{q}=\left(\frac{0.9 * \mathrm{fit}_{q}}{\max (\mathrm{fit})}\right)+0.1 \text {, }
$$

where fit $_{q}$ is the fitness value of the solution and $q$ is the proportional to the quality of egg in the nest position $q$.

If the host bird identifies the cuckoo egg, then the host bird may throw the egg away or leave that nest and built a new nest using (16). Otherwise the egg will grow and is alive for the next generation.

$$
\text { nest }_{q}=X_{q, \min }+\operatorname{rand}(0,1) *\left(X_{q, \max }-X_{q, \min }\right) .
$$

\subsection{Steps to Be Followed for Optimization}

Step 1. Run load flow analysis.

Step 2. Obtain the base power losses and voltage at each bus.

Step 3. Run the LSF and VSI to find the candidate location for DG and DSTATCOM.

Step 4. Set the lower and upper limits for the constraints.

Step 5. Initiate random population of $n$ host nests, $X_{i}$, for amount of $\mathrm{kW}$ or $\mathrm{kVAr}$ that will be injected within constraints.

Step 6. Obtain cuckoo randomly using Levy flights, $i$.

Step 7. Evaluate its fitness $\left(F_{i}\right)$ according to objective function.

Step 8. Get a nest randomly from population $j$.

Step 9. If $F_{i}>F_{j}$, then go to Step 11. If not, go to Step 12 .

Step 10. Let $j$ be the solution.

Step 11. Replace $j$ as the new solution.

Step 12. If a fraction of nest is replaced by new nests, then create a new nest at new location with the help of Levy flights.

Step 13. Choose the best current nests.

Step 14. Allow the current best solution to the next generation.

Step 15. If maximum iteration is not reached, then go to Step 6; otherwise it is the best nest (optimal solution).

Step 16. Display optimal solution.

These are the steps involved to minimize $F$.

\section{Test Result and Discussion}

In order to analyze the performance of the proposed method, it has been tested on IEEE 12-bus system, 34-bus system, and 69-bus system. The direct load flow analysis is used to find the power losses, voltage magnitude, and phase angle at various buses. For all the test systems, the substation voltage is considered as $1 \mathrm{p} . \mathrm{u}$. The load is assumed to be constant power load. The DG that is used in the test system is capable 
TABLE 1: Result of 12-bus system.

\begin{tabular}{|c|c|c|c|}
\hline Cases & & PSO [12] & Proposed method \\
\hline \multirow{6}{*}{ Only DG (Case II) } & $\begin{array}{l}\text { DG size in MW } \\
\text { (location) }\end{array}$ & $0.0378(9)$ & $0.2355(9)$ \\
\hline & Power loss $(\mathrm{kW})$ & 17.68 & 10.77 \\
\hline & $V_{\min }(\mathrm{p} . \mathrm{u})$ & NA & 0.9830 \\
\hline & VSI (p.u) & NA & 0.9340 \\
\hline & $\operatorname{TOC}(\$)$ & NA & 1220 \\
\hline & $\begin{array}{l}\text { Average computation } \\
\text { time }(\mathrm{s})\end{array}$ & NA & 12.12 \\
\hline \multirow{6}{*}{ Only DSTATCOM (Case III) } & $\begin{array}{l}\text { DSTATCOM (size and } \\
\text { location) }\end{array}$ & $0.0321(9)$ & $0.2102(9)$ \\
\hline & Power loss $(\mathrm{kW})$ & 18.40 & 12.58 \\
\hline & $V_{\min }(\mathrm{p} . \mathrm{u})$ & NA & 0.9562 \\
\hline & VSI (p.u) & NA & 0.8235 \\
\hline & $\operatorname{TOC}(\$)$ & NA & 1101.3 \\
\hline & $\begin{array}{c}\text { Average computation } \\
\text { time }(\mathrm{s})\end{array}$ & NA & 12.51 \\
\hline \multirow{6}{*}{$\begin{array}{l}\text { Both DG and DSTATCOM placed simultaneously } \\
\text { (Case IV) }\end{array}$} & $\begin{array}{l}\text { DG \& DSTATCOM (size } \\
\text { and location) }\end{array}$ & $\begin{array}{l}0.0390(9) \\
0.0320(9)\end{array}$ & $\begin{array}{c}0.2324(9) \\
0.2121(9)\end{array}$ \\
\hline & Power loss $(\mathrm{kW})$ & 11.05 & 3.17 \\
\hline & $V_{\min }(\mathrm{p} . \mathrm{u})$ & 0.9608 & 0.9908 \\
\hline & VSI (p.u) & NA & 0.9636 \\
\hline & $\operatorname{TOC}(\$)$ & NA & 2235.6 \\
\hline & $\begin{array}{l}\text { Average computation } \\
\text { time }(\mathrm{s})\end{array}$ & NA & 11.92 \\
\hline
\end{tabular}

of delivering only real power. The maximum limit of the DG unit is $60 \%$ of the total $\mathrm{kW}$ loading of the network. The maximum limit of the DSTATCOM unit is $100 \%$ of the total kVAr loading of the network. Regarding multiple DG and DSTATCOM, the maximum number of DG and DSTATCOM placement is limited to three, since, beyond this limit, there is no significant improvement in power loss reduction. The total operating cost (TOC) of DG and DSTATCOM is given by [11]

$$
\begin{aligned}
\text { TOC }= & \left(\beta_{1} *\right. \text { Ploss } \\
& +\left(\beta_{2} P_{\text {DGT or or DSTATCOMT }}\right)
\end{aligned}
$$

Let us assume that $\beta_{1}$ and $\beta_{2}$ are the cost coefficient and their values are $4 \$ / \mathrm{kW}$ or $\mathrm{kVAr}$ and $5 \$ / \mathrm{kW}$ or $\mathrm{kVAr}$, respectively.

The five different cases are considered to analyze the effectiveness of the proposed method.

Case I. The system is without DG and DSTATCOM units (base case).

Case II. The system is with only DG. Results are presented in Tables 1-3(a).

Case III. The system is with only DSTATCOM. Results are presented in Tables 1-3(a).
Case IV. The system is with single DG and DSTATCOM. Results are presented in Tables 1-3(a).

Case V. The system is with multiple DG and DSTATCOM. Results are presented in Table 3(b).

5.1. 12-Bus System. The IEEE 12-bus radial distribution system consists of 12 buses and 11 branches. The line data and bus data of this system are taken from [43]. The base values are $100 \mathrm{MVA}$ and $11 \mathrm{KV}$ and the total real and reactive power loads of this system are 0.435 MW and 0.405 MVAr, respectively. The loss sensitivity factor is calculated for all the nodes in order to find the optimal placement of DG for the cases II, IV, and V. As soon as the values of LSF are calculated, then the next step is to arrange all the values in descending order. The top most three values which are more sensitive are selected to install the DSTATCOM units in the system. The VSI are calculated for all the buses and then they are sorted in ascending order. The bus which has more sensitivity to voltage collapse is chosen to place the DSTATCOM units. These steps are to be followed for the cases III, IV, and V. In order to avoid incongruity in values, the existing method results are obtained using our load flow analysis.

Case I. The total power loss, minimum voltage, and minimum VSI of this case are $20.7 \mathrm{~kW}, 0.9431$ p.u., and 0.7912 p.u., respectively. 
TABLE 2: Result of 34-bus system.

\begin{tabular}{|c|c|c|c|}
\hline Cases & & PSO [12] & Proposed method \\
\hline \multirow{6}{*}{ Only DG case (II) } & DG (size and location) & $0.1996(21)$ & $2.3278(23)$ \\
\hline & Power loss (kW) & 203.98 & 98.42 \\
\hline & $V_{\min }(\mathrm{p} . \mathrm{u})$ & NA & 0.9740 \\
\hline & VSI (p.u) & NA & 0.8999 \\
\hline & TOC $(\$)$ & NA & 12032.6 \\
\hline & $\begin{array}{c}\text { Average computation } \\
\text { time }(\mathrm{s}) \\
\end{array}$ & NA & 11.41 \\
\hline \multirow{6}{*}{ Only DSTATCOM (Case III) } & $\begin{array}{l}\text { DSTATCOM (size and } \\
\text { location) }\end{array}$ & $0.1606(21)$ & $1.3705(23)$ \\
\hline & Power loss $(\mathrm{kW})$ & 212.96 & 175.01 \\
\hline & $V_{\min }(\mathrm{p} \cdot \mathrm{u})$ & NA & 0.9488 \\
\hline & VSI (p.u) & NA & 0.8105 \\
\hline & TOC $(\$)$ & NA & 7552.5 \\
\hline & $\begin{array}{l}\text { Average computation } \\
\text { time }(\mathrm{s})\end{array}$ & NA & 11.52 \\
\hline \multirow{6}{*}{$\begin{array}{l}\text { Both DG and DSTATCOM placed simultaneously } \\
\text { (Case IV) }\end{array}$} & $\begin{array}{l}\text { DG \& DSTATCOM (size } \\
\text { and location) }\end{array}$ & $\begin{array}{l}0.1371(21) \\
0.1634(21)\end{array}$ & $\begin{array}{l}2.3905(23) \\
1.3419(23)\end{array}$ \\
\hline & Power loss (kW) & 177.10 & 55.03 \\
\hline & $V_{\min }(\mathrm{p} . \mathrm{u})$ & 0.9483 & 0.9771 \\
\hline & VSI (p.u) & NA & 0.9115 \\
\hline & TOC $(\$)$ & NA & 18882.1 \\
\hline & $\begin{array}{l}\text { Average computation } \\
\text { time }(\mathrm{s})\end{array}$ & NA & 11.69 \\
\hline
\end{tabular}

Case II. In this case the DG units are optimally placed at 9th bus with the optimal size of $0.2355 \mathrm{MW}$. Because of this the power losses of this case have been reduced to $10.77 \mathrm{~kW}$ from $20.7 \mathrm{~kW}$. The minimum voltage and minimum VSI of this case are found to be 0.9830 p.u. and 0.9340 p.u., respectively.

Case III. The power losses of this case are reduced to $12.58 \mathrm{~kW}$ from $20.7 \mathrm{~kW}$ after placement of DSTATCOM units of $0.2102 \mathrm{MW}$ at bus 9. The voltage profile and minimum VSI of this case have been improved as 0.9562 p.u. and 0.8235 p.u., respectively.

Case IV. In this case the single DG and DSTATCOM are placed simultaneously at 9th bus and the size of the DG and DSTATCOM units is $0.2324 \mathrm{MW}$ and $0.2121 \mathrm{MVAr}$, respectively. The voltage profile and minimum VSI have been improved to 0.9908 p.u. and 0.9636 p.u. and they are 0.9431 p.u. and 0.7912 p.u. before placement of DG and DSTATCOM. As a result the total power losses of the system have been reduced to $3.17 \mathrm{~kW}$ from $20.7 \mathrm{~kW}$.

Case V. Regarding this case, the multiple DG and DSTATCOM are placed simultaneously at 7 th bus $(0.075+$ $j 0.11 \mathrm{MVA})$, 9th bus $(0.09+j 0.075 \mathrm{MVA})$, and 12th bus $(0.065+j 0.10 \mathrm{MVA})$, respectively, so that the total power losses of this case are reduced to $1.34 \mathrm{~kW}$ from $20.7 \mathrm{~kW}$.
Figures 2(a) and 2(b) show the comparison of power losses and voltage profile of the system under different cases discussed in this paper.

5.2. 34-Bus System. This is a medium scale radial distribution system with 34 buses and 33 branches. The line data and load data are taken from [44]. The base values are $100 \mathrm{MVA}$ and $11 \mathrm{KV}$ and the total real and reactive power loads of the system are 3.715 MW and 2.3 MVAr, respectively.

Case I. The total power loss, minimum voltage, and minimum VSI of this case are $0.2213 \mathrm{MW}, 0.9420$ p.u., and 0.7875 p.u., respectively.

Case II. In this case the DG units are optimally placed at $23 \mathrm{rd}$ bus with the size of $2.3278 \mathrm{MW}$. Because of this the power losses in this case have been reduced to $98.42 \mathrm{~kW}$ from $221.2860 \mathrm{~kW}$. The minimum voltage and minimum VSI of this case are found to be 0.9740 p.u. and 0.8999 p.u., respectively.

Case III. The power losses of this case are reduced to $175.01 \mathrm{~kW}$ from $221.2860 \mathrm{~kW}$ after placement of DSTATCOM units of $1.3705 \mathrm{MW}$ at bus 23 . The voltage profile and minimum VSI of this case have been improved as 0.9488 p.u. and 0.8105 p.u., respectively. 
TABLE 3

(a) Result of 69-bus system

\begin{tabular}{|c|c|c|c|}
\hline Cases & & PSO [12] & Proposed method \\
\hline \multirow{6}{*}{ Only DG (Case II) } & DG (location) & $1.8761(61)$ & $1.8727(61)$ \\
\hline & Power loss (kW) & 83.22 & 83.21 \\
\hline & $V_{\min }(\mathrm{p} . \mathrm{u})$ & NA & 0.9682 \\
\hline & VSI (p.u) & NA & 0.8788 \\
\hline & TOC $(\$)$ & NA & 9696.3 \\
\hline & $\begin{array}{c}\text { Average computation } \\
\text { time }(\mathrm{s}) \\
\end{array}$ & NA & 12.54 \\
\hline \multirow{6}{*}{ Only DSTATCOM (Case III) } & $\begin{array}{l}\text { DSTATCOM (size and } \\
\text { location) }\end{array}$ & $0.9011(61)$ & $1.200(61)$ \\
\hline & Power loss $(\mathrm{kW})$ & 159.38 & 152.95 \\
\hline & $V_{\min }(\mathrm{p} . \mathrm{u})$ & NA & 0.9285 \\
\hline & VSI (p.u) & NA & 0.7375 \\
\hline & $\operatorname{TOC}(\$)$ & NA & 6611.8 \\
\hline & $\begin{array}{c}\text { Average computation } \\
\text { time }(\mathrm{s})\end{array}$ & NA & 12.84 \\
\hline \multirow{6}{*}{$\begin{array}{l}\text { Both DG and DSTATCOM placed simultaneously } \\
\text { (Case IV) }\end{array}$} & $\begin{array}{l}\text { DG \& DSTATCOM (size } \\
\text { and location) }\end{array}$ & $\begin{array}{l}0.1223(61) \\
0.9045(61)\end{array}$ & $\begin{array}{l}1.7500(61) \\
1.15(61)\end{array}$ \\
\hline & Power loss $(\mathrm{kW})$ & 32.56 & 24.15 \\
\hline & $V_{\min }(\mathrm{p} . \mathrm{u})$ & NA & 0.9715 \\
\hline & VSI (p.u) & NA & 0.8908 \\
\hline & TOC $(\$)$ & NA & 14596.6 \\
\hline & $\begin{array}{l}\text { Average computation } \\
\text { time }(\mathrm{s})\end{array}$ & NA & 12.35 \\
\hline
\end{tabular}

(b) Result of multiple DG and DSTATCOM placement (Case V)

\begin{tabular}{|c|c|c|c|}
\hline & 12-bus system & 34-bus system & 69-bus system \\
\hline DG size in MW (location) & $\begin{array}{c}0.075(7) \\
0.09(9) \\
0.065(12)\end{array}$ & $\begin{array}{l}1.90(23) \\
0.77(32) \\
0.10(34)\end{array}$ & $\begin{array}{l}0.49(17) \\
1.40(61) \\
0.25(63)\end{array}$ \\
\hline DSTATCOM size in MVAr (location) & $\begin{array}{c}0.11(7), \\
0.075(9) \\
0.10(12) \\
\end{array}$ & $\begin{array}{l}0.65(11) \\
0.85(19) \\
0.75(25) \\
\end{array}$ & $\begin{array}{l}0.27(25), \\
0.98(61), \\
0.20(63)\end{array}$ \\
\hline Power loss $(\mathrm{kW})$ & 1.34 & 19.32 & 8.07 \\
\hline$V_{\min }(\mathrm{p} . \mathrm{u})$ & 0.9947 & 0.9919 & 0.9925 \\
\hline VSI (p.u) & 0.9778 & 0.9682 & 0.9587 \\
\hline TOC (\$) & 2580.4 & 26327 & 17982 \\
\hline Average computational time (s) & 11.98 & 12.12 & 12.56 \\
\hline
\end{tabular}

Case IV. In this case the single DG and DSTATCOM are placed simultaneously at 23rd bus and the optimal size of the DG and DSTATCOM units is 2.3905 MW and 1.3419 MVAr, respectively. The voltage profile and minimum VSI have been improved to 0.9771 p.u. and 0.9115 p.u. and they are 0.9420 p.u. and 0.7875 p.u. before placement of DG and DSTATCOM. The total real power losses of this case are $55.03 \mathrm{~kW}$.

Case V. Regarding this case, the multiple DG and DSTATCOMare placed simultaneously at 23rd bus (1.9+ $j 0.65 \mathrm{MVA})$, 32 nd bus $(0.77+j 0.85 \mathrm{MVA})$, and 34th bus (0.10+j $0.75 \mathrm{MVA})$, respectively. The total power losses are reduced to $19.32 \mathrm{~kW}$ after the placement of multiple DG and DSTATCOM.

Figures 3(a) and 3(b) show the comparison of power losses and voltage profile of the system under different cases discussed in this paper.

5.3. 69-Bus System. This is a large scale radial distribution system with 69 buses and 68 branches. The line and bus data of this system are taken from [45]. The base values are $100 \mathrm{MVA}$ and $12.66 \mathrm{KV}$ and the total real and reactive power loads are 3.80 MW and 2.69 MVAr, respectively. 


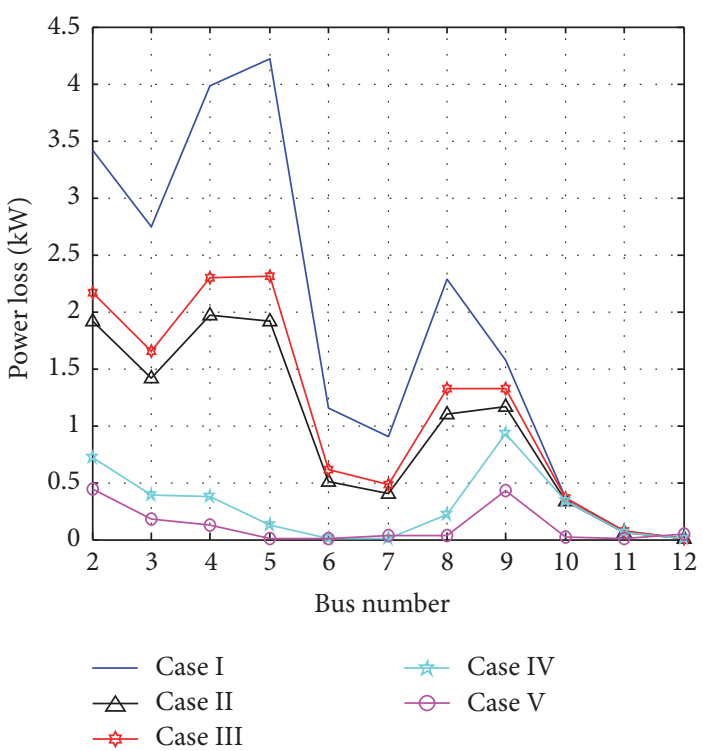

(a)

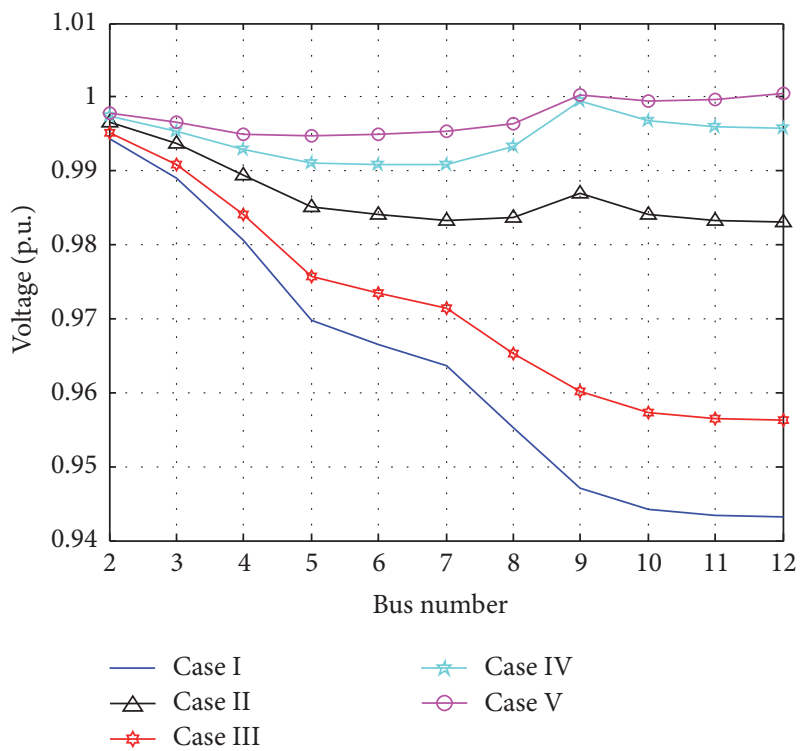

(b)

FIGURE 2: (a) Comparison of line losses for different cases in 12-bus system. (b) Comparison of voltage profile for different cases in 12-bus system.

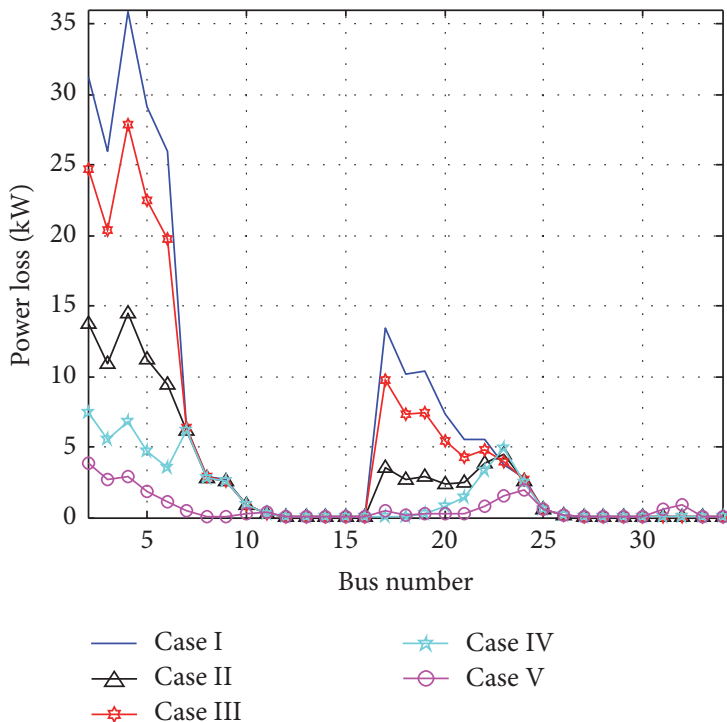

(a)

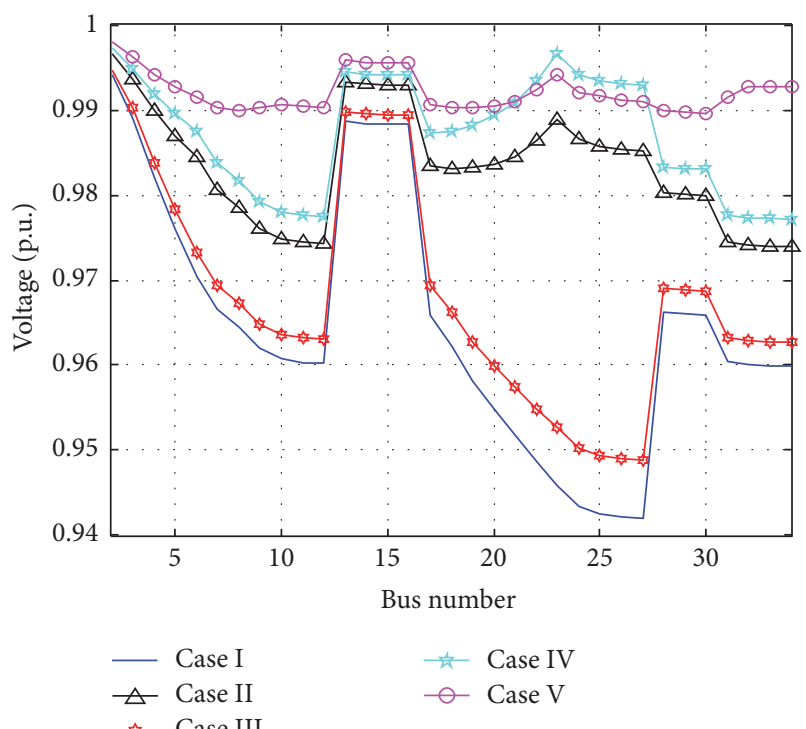

(b)

Figure 3: (a) Comparison of line losses for different cases in 34-bus system. (b) Comparison of voltage profile for different cases in 34-bus system.

Case I. The total power loss, minimum voltage, and minimum VSI of the system are $0.255 \mathrm{MW}, 0.9090$ p.u., and 0.6822 p.u., respectively.

Case II. In this case the DG units are optimally placed at 61st bus with the optimal size of $1.8727 \mathrm{MW}$. Because of this the power losses in this case are reduced to $83.21 \mathrm{~kW}$ from $225 \mathrm{~kW}$. The minimum voltage and minimum VSI of this case are found to be 0.9682 p.u. and 0.8788 p.u., respectively.
Case III. The power losses of this case are reduced to $152.95 \mathrm{~kW}$ from $225 \mathrm{~kW}$ after placement of DSTATCOM units of $1.200 \mathrm{MW}$ at bus 61 . The voltage profile and minimum VSI of this case have been improved as 0.9285 p.u. and 0.7375 p.u., respectively.

Case IV. In this case the single DG and DSTATCOM are placed simultaneously at 61st bus and the size of the DG and DSTATCOM units is $1.75 \mathrm{MW}$ and 1.15 MVAr, respectively. 


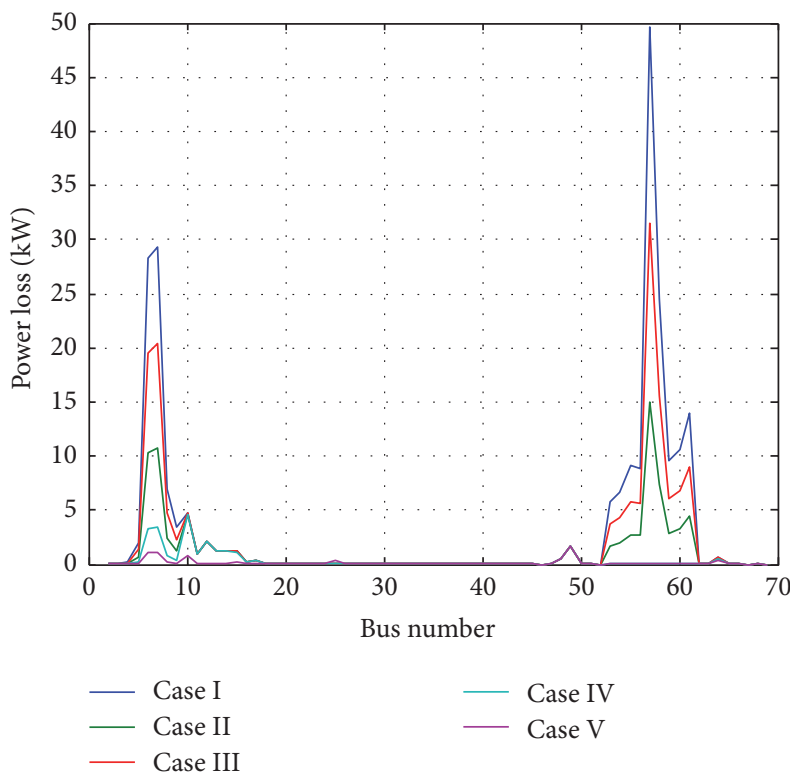

(a)

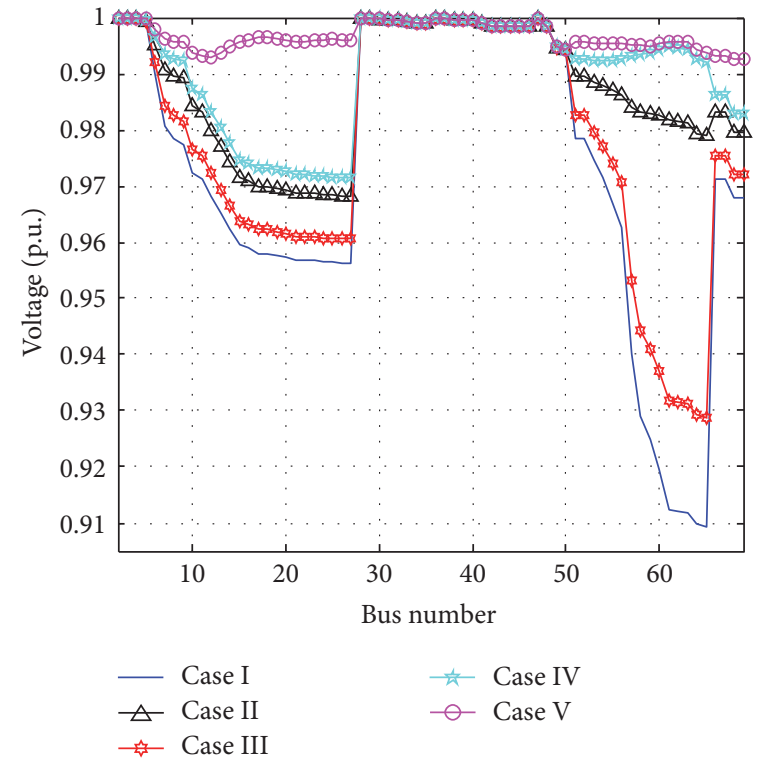

(b)

Figure 4: (a) Comparison of line losses for different cases in 69-bus system. (b) Comparison of voltage profile for different cases in 69-bus system.

The voltage profile and minimum VSI have been improved to 0.9715 p.u. and 0.8908 p.u. and it is 0.9090 p.u. and 0.6822 p.u. before placement of DG and DSTATCOM. The total real power losses of this case are reduced to $24.15 \mathrm{~kW}$.

Case V. Regarding this case, the multiple DG and DSTATCOM are placed simultaneously at 17 th bus $(0.49+$ $j 0.27 \mathrm{MVA}), 61 \mathrm{st}$ bus $(1.40+j 0.98 \mathrm{MVA})$, and 63rd bus $(0.25+j 0.20 \mathrm{MVA})$, respectively. The total power losses are reduced to $8.07 \mathrm{~kW}$ after the placement of multiple DG and DSTATCOM.

Figures 4(a) and 4(b) show the comparison of voltage profile and power losses of the system under different cases discussed in this paper.

Overall Analysis. When compared with all the cases, it is very clear that the prodigious improvement in the voltage profile and satisfactory power losses reduction was achieved using case V (i.e., simultaneous placement of multiple DG and DSTATCOM units) as presented in Table 3(b). Hence it is recommend to install simultaneous placement of multiple DG and DSTATCOM units in distribution system to achieve maximum benefits of the system. The simulation results are compared with PSO method and it was found that the result obtained by the CSA method gives encouraging results. Since the existing method's computational time is not available, the computational efficiency in terms of CPU time of the CSA method could not be compared with other methods.

\section{Conclusion}

Simultaneous allocation of DG and DSTATCOM in the radial distribution system is used to compensate the real and reactive power which leads to reducing system power loss, voltage profile enhancement, power factor correction, load balancing, power quality improvement, on-peak operating costs reduction, system stability improvement, pollutant emission reduction, and increased overall energy efficiency. It is essential to place the DGs and DSTATCOMs at candidate locations with optimal $\mathrm{kW}$ and $\mathrm{kVAr}$ to ensure the maximum benefits of the system. In this work, an integrated approach has been used to find the optimal locations of DG and DSTATCOM in the RDS. The sizing of the both compensating devices can be obtained by using cuckoo search algorithm. The main advantage of using CSA is that it does not need to spend more effort in tuning the control parameters, as in the case of GA, PGS, MINLP, DSA, and other evolutionary algorithms. The proposed method is applied to IEEE 12-bus, 34-bus, and 69-bus radial distribution system with different cases. The simulated results obtained using CSA are compared with the other existing techniques, and the results show that the performance of the proposed method for minimization of power loss and maximization of voltage profile is found to be better than the other existing methods. From the above discussion it can be concluded that the proposed method can be easily applied to any large scale and real time distribution system.

\section{Competing Interests}

The authors declare that there is no conflict of interests regarding the publication of this paper.

\section{Acknowledgments}

The authors gratefully acknowledge support from the management at VIT University, Vellore, India. 


\section{References}

[1] J. A. Martín García and A. J. Gil Mena, "Optimal distributed generation location and size using a modified teachinglearning based optimization algorithm," International Journal of Electrical Power and Energy Systems, vol. 50, no. 1, pp. 65-75, 2013.

[2] A. Mohamed Imran, M. Kowsalya, and D. P. Kothari, "A novel integration technique for optimal network reconfiguration and distributed generation placement in power distribution networks," International Journal of Electrical Power and Energy Systems, vol. 63, pp. 461-472, 2014.

[3] A. A. El-Fergany, "Optimal capacitor allocations using evolutionary algorithms," IET Generation, Transmission and Distribution, vol. 7, no. 6, pp. 593-601, 2013.

[4] M. H. Moradi, A. Zeinalzadeh, Y. Mohammadi, and M. Abedini, "An efficient hybrid method for solving the optimal sitting and sizing problem of DG and shunt capacitor banks simultaneously based on imperialist competitive algorithm and genetic algorithm," International Journal of Electrical Power and Energy Systems, vol. 54, pp. 101-111, 2014.

[5] K. R. Devabalaji, K. Ravi, and D. P. Kothari, "Optimal location and sizing of capacitor placement in radial distribution system using Bacterial Foraging Optimization Algorithm,' International Journal of Electrical Power and Energy Systems, vol. 71, pp. 383-390, 2015.

[6] S. Gopiya Naik, D. K. Khatod, and M. P. Sharma, "Optimal allocation of combined DG and capacitor for real power loss minimization in distribution networks," International Journal of Electrical Power and Energy Systems, vol. 53, pp. 967-973, 2013.

[7] B.-S. Chen and Y.-Y. Hsu, "A minimal harmonic controller for a STATCOM," IEEE Transactions on Industrial Electronics, vol. 55, no. 2, pp. 655-664, 2008.

[8] K. R. Devabalaji and K. Ravi, "Power quality improvement in wind farm connected to grid using STATCOM," in Proceedings of the International Conference on Advances in Electrical Engineering (ICAEE '14), pp. 1-5, Unnao, India, January 2014.

[9] A. Valderrábano and J. M. Ramirez, "DStatCom regulation by a fuzzy segmented PI controller," Electric Power Systems Research, vol. 80, no. 6, pp. 707-715, 2010.

[10] M. Hosseini, H. A. Shayanfar, and M. Fotuhi-Firuzabad, "Modeling of static series voltage regulator (SSVR) in distribution systems for voltage improvement and loss reduction," Leonardo Electronic Journal of Practices and Technologies, vol. 7, no. 12, 2008.

[11] I. A. Mohamed and M. Kowsalya, "Optimal size and siting of multiple distributed generators in distribution system using bacterial foraging optimization," Swarm and Evolutionary Computation, vol. 15, pp. 58-65, 2014.

[12] S. Devi and M. Geethanjali, "Optimal location and sizing determination of Distributed Generation and DSTATCOM using Particle Swarm Optimization algorithm," International Journal of Electrical Power and Energy Systems, vol. 62, pp. 562570, 2014.

[13] S. Jazebi, S. H. Hosseinian, and B. Vahidi, "DSTATCOM allocation in distribution networks considering reconfiguration using differential evolution algorithm," Energy Conversion and Management, vol. 52, no. 7, pp. 2777-2783, 2011.

[14] S. A. Taher and S. A. Afsari, "Optimal location and sizing of DSTATCOM in distribution systems by immune algorithm," International Journal of Electrical Power and Energy Systems, vol. 60, pp. 34-44, 2014.
[15] M. Farhoodnea, A. Mohamed, H. Shareef, and H. Zayandehroodi, "Optimum D-STATCOM placement using firefly algorithm for power quality enhancement," in Proceedings of the IEEE 7th International Power Engineering and Optimization Conference (PEOCO '13), pp. 98-102, Langkawi Island, Malaysia, June 2013.

[16] A. Bagherinasab, M. Zadehbagheri, S. Abdul Khalid, M. Gandomkar, and N. A. Azli, "Optimal placement of D-STATCOM using hybrid genetic and ant colony algorithm to losses reduction," International Journal of Applied Power Engineering, vol. 2, no. 2, pp. 53-60, 2013.

[17] T. Yuvaraj, K. Ravi, and K. R. Devabalaji, "DSTATCOM allocation in distribution networks considering load variations using bat algorithm," Ain Shams Engineering Journal, 2015.

[18] T. Yuvaraj, K. Devabalaji, and K. Ravi, "Optimal placement and sizing of DSTATCOM using harmony search algorithm," Energy Procedia, vol. 79, pp. 759-765, 2015.

[19] A. Tah and D. Das, "Novel analytical method for the placement and sizing of distributed generation unit on distribution networks with and without considering P and PQV buses," International Journal of Electrical Power and Energy Systems, vol. 78, pp. 401-413, 2016.

[20] S. R. Gampa and D. Das, "Optimum placement and sizing of DGs considering average hourly variations of load," International Journal of Electrical Power and Energy Systems, vol. 66, pp. 25-40, 2015.

[21] R. Kollu, S. R. Rayapudi, and V. L. N. Sadhu, "A novel method for optimal placement of distributed generation in distribution systems using HSDO," International Transactions on Electrical Energy Systems, vol. 24, no. 4, pp. 547-561, 2014.

[22] S. Ganguly, N. C. Sahoo, and D. Das, "Multi-objective particle swarm optimization based on fuzzy-Pareto-dominance for possibilistic planning of electrical distribution systems incorporating distributed generation," Fuzzy Sets and Systems. An International Journal in Information Science and Engineering, vol. 213, pp. 47-73, 2013.

[23] J. A. Martín García and A. J. Gil Mena, "Optimal distributed generation location and size using a modified teaching learning based optimization algorithm," International Journal of Electrical Power and Energy Systems, vol. 50, no. 1, pp. 65-75, 2013.

[24] R. S. Rao, K. Ravindra, K. Satish, and S. V. L. Narasimham, "Power loss minimization in distribution system using network reconfiguration in the presence of distributed generation," IEEE Transactions on Power Systems, vol. 28, no. 1, pp. 317-325, 2013.

[25] S. Kansal, V. Kumar, and B. Tyagi, "Optimal placement of different type of DG sources in distribution networks," International Journal of Electrical Power and Energy Systems, vol. 53, no. 1, pp. 752-760, 2013

[26] D. K. Khatod, V. Pant, and J. Sharma, "Evolutionary programming based optimal placement of renewable distributed generators,' IEEE Transactions on Power Systems, vol. 28, no. 2, pp. 683-695, 2013.

[27] S. Ganguly, N. C. Sahoo, and D. Das, "A novel multi-objective PSO for electrical distribution system planning incorporating distributed generation," Energy Systems, vol. 1, no. 3, pp. 291-337, 2010.

[28] X. S. Yang and S. Deb, "Cuckoo search via Lévy flights," in Proceedings of the World Congress on Nature \& Biologically Inspired Computing (NaBIC '09), pp. 210-214, IEEE Publications, Coimbatore, India, December 2009. 
[29] X.-S. Yang and S. Deb, "Cuckoo search: recent advances and applications," Neural Computing and Applications, vol. 24, no. 1, pp. 169-174, 2014.

[30] S. Dejam, M. Sadeghzadeh, and S. J. Mirabedini, "Combining cuckoo and tabu algorithms for solving quadratic assignment problems," Journal of Academic and Applied Studies, vol. 2, pp. $1-8,2012$.

[31] S. Walton, O. Hassan, K. Morgan, and M. R. Brown, "A review of the development and applications of the cuckoo search algorithm," in Swarm Intelligence and Bio-Inspired Computation, X.S. Yang, Z. Cui, R. Xiao, A. H. Gandomi, and M. Karamanoglu, Eds., pp. 257-271, Elsevier, Oxford, UK, 2013.

[32] X.-S. Yang and S. Deb, "Engineering optimisation by cuckoo search," International Journal of Mathematical Modelling and Numerical Optimisation, vol. 1, no. 4, pp. 330-343, 2010.

[33] K. Chandrasekaran and S. P. Simon, "Multi-objective scheduling problem: hybrid approach using fuzzy assisted cuckoo search algorithm," Swarm and Evolutionary Computation, vol. 5, pp. 1-16, 2012.

[34] E. Valian, S. Tavakoli, S. Mohanna, and A. Haghi, "Improved cuckoo search for reliability optimization problems," Computers and Industrial Engineering, vol. 64, no. 1, pp. 459-468, 2013.

[35] Z. Moravej and A. Akhlaghi, "A novel approach based on cuckoo search for DG allocation in distribution network," International Journal of Electrical Power and Energy Systems, vol. 44, no. 1, pp. 672-679, 2013.

[36] M. Basu and A. Chowdhury, "Cuckoo search algorithm for economic dispatch,” Energy, vol. 60, no. 1, pp. 99-108, 2013.

[37] T. T. Nguyen, A. V. Truong, and T. A. Phung, "A novel method based on adaptive cuckoo search for optimal network reconfiguration and distributed generation allocation in distribution network," International Journal of Electrical Power and Energy Systems, vol. 78, pp. 801-815, 2016.

[38] J.-H. Teng, "A direct approach for distribution system load flow solutions," IEEE Transactions on Power Delivery, vol. 18, no. 3, pp. 882-887, 2003.

[39] K. Prakash and M. Sydulu, "Particle swarm optimization based capacitor placement on radial distribution systems," in Proceedings of the IEEE Power Engineering Society General Meeting (PES '07), Tampa, Fla, USA, June 2007.

[40] K. R. Devabalaji and K. Ravi, "Optimal size and siting of multiple DG and DSTATCOM in radial distribution system using bacterial foraging optimization algorithm," Ain Shams Engineering Journal, pp. 959-971, 2015.

[41] M. Chakravorty and D. Das, "Voltage stability analysis of radial distribution networks," International Journal of Electrical Power and Energy System, vol. 23, no. 2, pp. 129-135, 2001.

[42] K. R. Devabalaji, T. Yuvaraj, and K. Ravi, "An efficient method for solving the optimal sitting and sizing problem of capacitor banks based on cuckoo search algorithm," Ain Shams Engineering Journal, In press.

[43] D. Das, H. S. Nagi, and D. P. Kothari, "Novel method for solving radial distribution networks," IEE Proceedings: Generation, Transmission and Distribution, vol. 141, no. 4, 1994.

[44] M. Chis, M. Salama, and S. Jayaram, "Capacitor placement in distribution systems using heuristic search strategies," IEE Proceedings-Generation, Transmission and Distribution, vol. 144, no. 3, pp. 225-230, 1997.

[45] N. C. Sahoo and K. Prasad, "A fuzzy genetic approach for network reconfiguration to enhance voltage stability in radial distribution systems," Energy Conversion and Management, vol. 47, no. 18-19, pp. 3288-3306, 2006. 


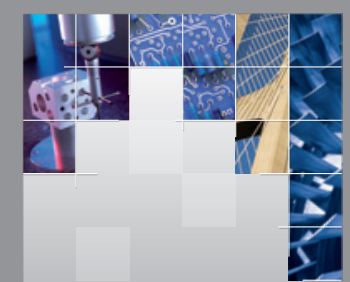

\section{Enfincering}
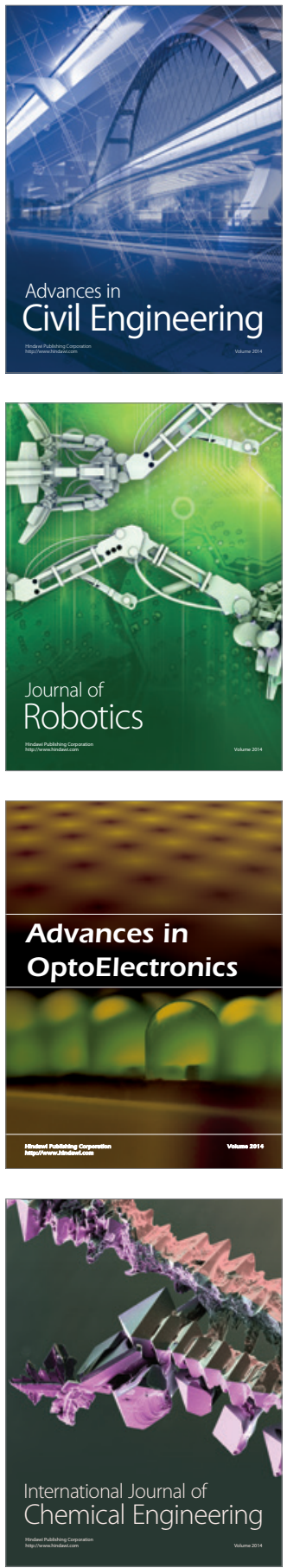

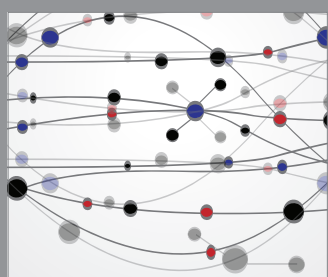

The Scientific World Journal

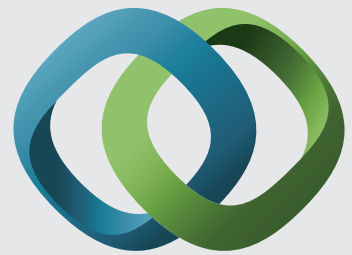

\section{Hindawi}

Submit your manuscripts at

https://www.hindawi.com
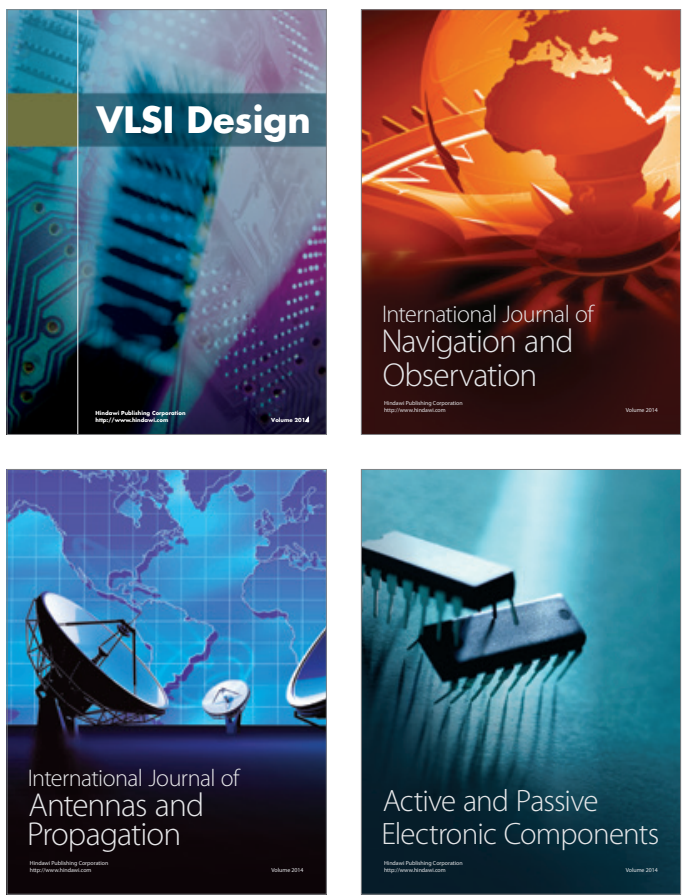
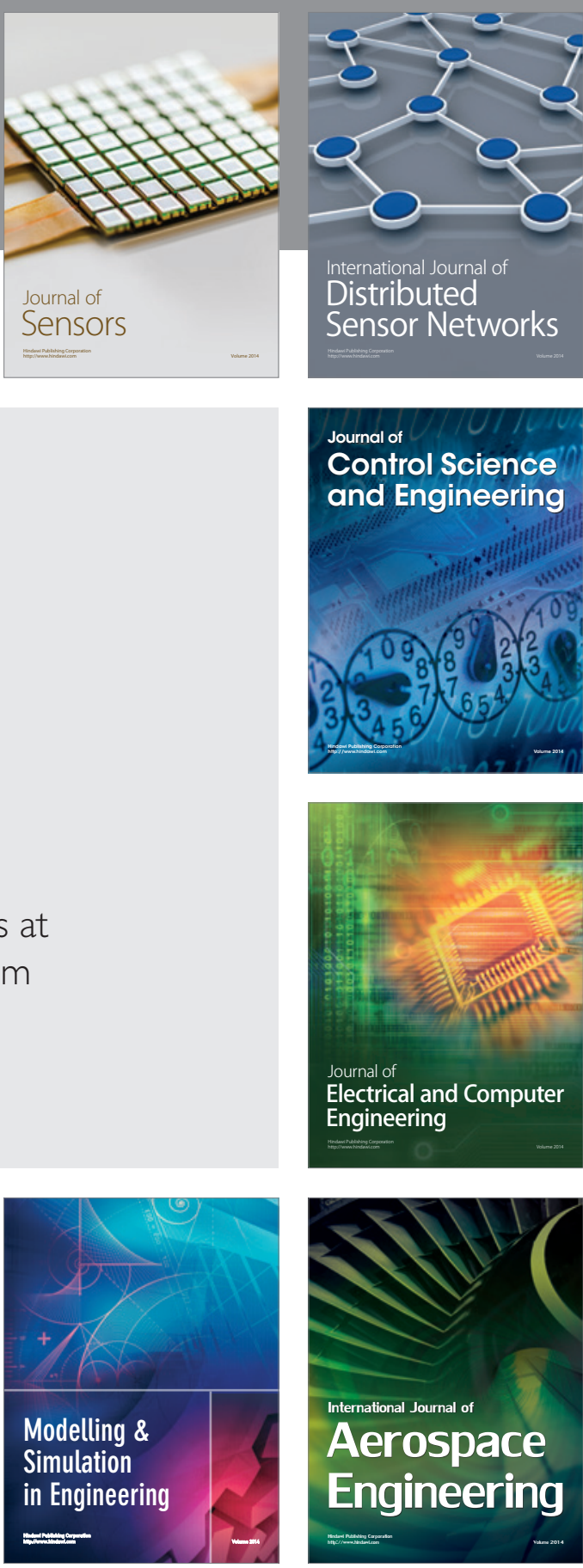

International Journal of

Distributed

Sensor Networks

$-$

Joumal of

Control Science

and Engineering
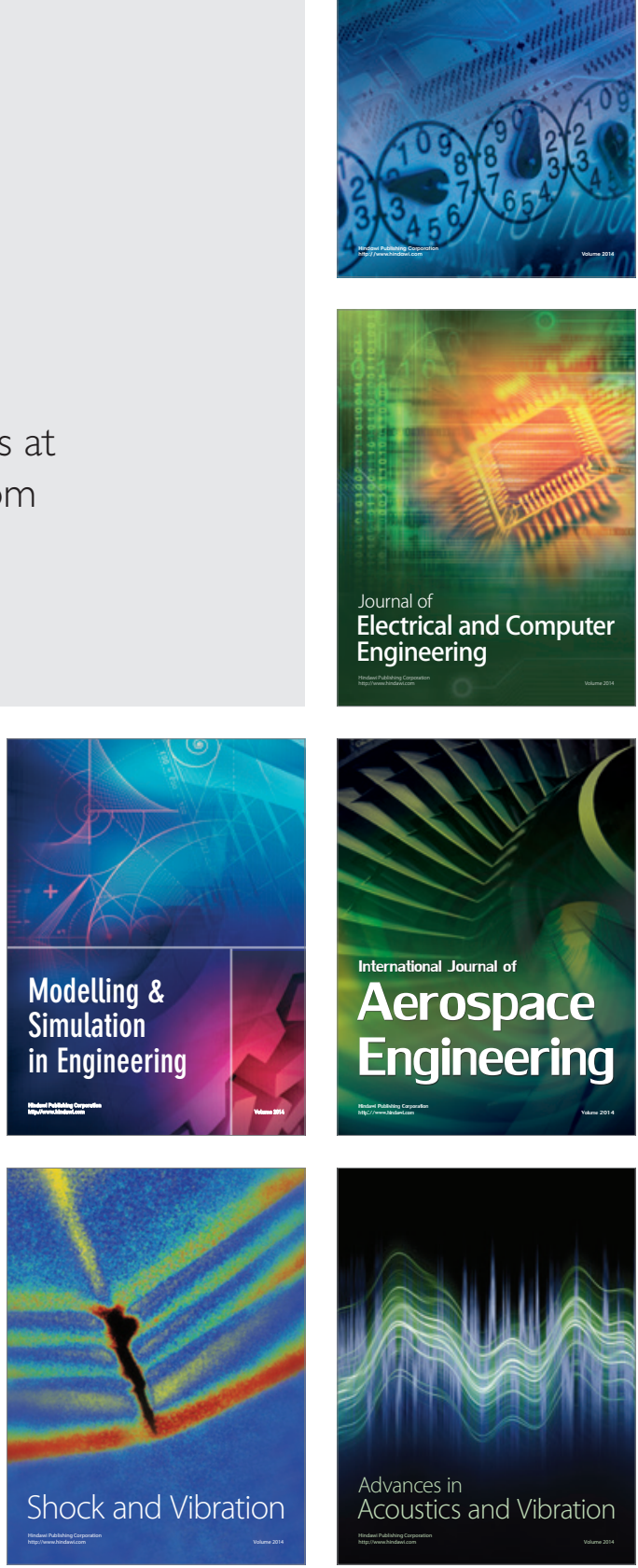